\title{
Editorial
}

\section{Coming together for Progress}

Progress by definition is a variable term; although the dictionary definition is 'forward or onward movement toward a destination', many times progress is defined by change, or to put it more scientifically, by evolution. That is what we see today in the Asian Foot and Ankle surgery sphere, with the coming together of two like-minded academic bodies, and the merger giving birth to a scientific journal of international standards.

The Indian Foot and Ankle Society, started in 1986, had always been keen on academic documentation and publications. It was mooted at the inception of the Society itself to bring out a journal on foot and ankle problems and related research as its official publication, with Dr S Pandey being tasked with the production and publishing. The maiden issue of the Journal of Foot Surgery was released at the inaugural conference at Cuttack, by the past President of SICOT, Mr KT Dholakia on 23 October 1986. This evolved further, under editorial guidance of Dr MS Dhillon and Dr RAAgrawal, and then back to the former, evolving from a single annual issue, to a bi-annual issue and ultimately an online portal, evolving into the Indian Journal of Foot and Ankle Surgery.

The Asia-Pacific Society for Foot and Ankle Surgery (APSFAS) was first proposed by Dr Kang-lai Tang in conjunction with Dr Zheng-yi Wang, Dr Bao-guo Jiang, and Dr Guang-rong Yu at the 13th Annual Meeting of the Chinese Orthopedic Foot and Ankle Society (COFAS) and the Second International Symposium of Foot and Ankle Surgery, held on October 2009 in Chongqing, China. Senior Indian surgeons like Dr SS Jha and Dr S Pandey then discussed with Dr Tang and colleagues that a pan-Asian journal may be the need of the hour to address the problems of the region, and act as a vehicle to present their academic research.

Thus was born the Journal of Foot and Ankle Surgery (Asia-Pacific) in its current avatar.

The journal focuses on the following areas of interest specific to Asian and other developing countries; wound care, bone healing, pain management, paralytic foot, orthotics and epidemiology of conditions in the specific to Asia, diabetes and even sports medicine. Some medical problems are unique to our region; the Asian tribune reported recently that in India about 45,000 lower limb amputations take place every year. An Indian study showed that $50 \%$ of people, who underwent diabetes-related lower limb amputations died within three years; this is indeed very alarming, and needs local solutions which can be encouraged by local research. Studies focused on local populations ${ }^{1}$ highlight the problems encountered by both the patients and the doctors, and this journal is the ideal vehicle for publishing such data.

The epidemiology of Asian Foot and Ankle problems has also been documented to be different from the rest of the world. ${ }^{2,3}$ Some injuries are also unique, due to road conditions and unique transport methods. ${ }^{3,4}$ This needs a vehicle for data propagation, and thus this journal fits into a nice slot that fulfills the need of the hour, and we hope it develops into the formal voice of the Asian foot surgeons.

With this in mind, we present the inaugural issue of the JFAS (AP); the authors of the publications in this issue are from diverse countries, presenting different viewpoints, but it gels together nicely as a comprehensive overview of diverse aspects of the anatomical region. We hope that in future more members will submit their research articles, case reports as well as reviews to this journal, helping us to enhance the publication in particular and the Asian Foot surgeons view points as a whole.

Let the newborn develop into an inter-active and scholarly tome of the future.

\section{REFERENCES}

1. Yusof MI, Sulaiman AR, Muslim DA. Diabetic foot complications: a two-year review of limb amputation in a Kelantanese population. Singapore Med J 2007;48(8):729-732.

2. Chotigavanichaya C, Leurmsumran P, Eamsobhana P, Sanpakit S, Kaewpornsawan K. The incidence of common orthopaedic problems in newborn at Siriraj Hospital. J Med Assoc Thai 2012;95 Suppl 9:S54-61.

3. Dhillon MS, Aggarwal S, Dhatt S, Jain M. Epidemiological pattern of foot injuries in India: preliminary assessment of data from a tertiary hospital. J Postgrad Med Edu Res 2012;46(3):144-147.

4. Agarwal A, Pruthi M. Bicycle-spoke injuries of the foot in children. J Orthop Surg (Hong Kong) 2010;18(3):338-341.

Mandeep S Dhillon Kang-lai Tang

Editors-in-Chief 